\title{
An Air Quality Forecasting tool over Italy (ForeChem)
}

\author{
Gabriele Curci \\ CETEMPS - Dip. Fisica, Università degli Studi dell'Aquila, Via Vetorio, 67010 Coppito, \\ L'Aquila, Italy \\ e-mail: gabriele.curci@aquila.infn.it
}

\begin{abstract}
The MM5-CHIMERE regional modelling system is implemented over Italy and validated against available ground-based observations of atmospheric composition in summer. MM5 meteorological model is run on two nested domain covering Europe and Italy at respectively 36 and $12 \mathrm{~km}$ horizontal resolution. CHIMERE chemistry transport model is used to simulate gas and aerosol composition on the two domains at $0.5^{\circ}$ and $0.15^{\circ}$ horizontal resolution. Anthropogenic hourly emissions of primary pollutants over Italy are derived from the CTN-ACE inventory developed by national environmental agencies. Biogenic volatile organic compound emissions are calculated with MEGAN model driven by MM5 radiation and temperature fields. Ozone $\left(\mathrm{O}_{3}\right)$ daily maxima are simulated with good correlation (0.76) and overestimated by $10 \%$. Model overestimation decreases with increasing observed $\mathrm{O}_{3}$, while correlation increases. $\mathrm{PM}_{10}$ is underestimated by $30-40 \%$ and reproduced with a correlation $>0.5$. Over Italy, the model capture enhanced level of $\mathrm{O}_{3}$, but not that of PM. Model skills in the three-day ahead forecast do not degrade rapidly. Graphical output of forecast is operationally available on the ForeChem web site: http://pumpkin.aquila.infn.it/forechem/.
\end{abstract}

\section{Introduction}

Air Quality forecast modelling systems are becoming more and more common throughout European countries [1], particularly in response to the need for short and long term actions aimed at reducing air pollution impact on human health [2]. In the last decade, the availability of increased computer power allowed the development of progressively more sophisticated and resolved three-dimensional "deterministic" atmospheric models, which have now almost completely substituted the more simplified and computationally efficient "statistical" models [1]. At European scale there are many models providing operational three-days ahead forecast at about $50 \mathrm{~km}$ horizontal resolution for ozone $\left(\mathrm{O}_{3}\right)$, nitrogen dioxide $\left(\mathrm{NO}_{2}\right)$, particulate matter with aerodynamic diameter less than $10 \mu \mathrm{m}\left(\mathrm{PM}_{10}\right)$, and other pollutants. Some of these forecasts are collected in an ensemble in the frame of European Monitoring Atmospheric Composition and Climate (MACC) project (http://www.gmes-atmosphere.eu/). In Italy there are several groups developing and running regional atmospheric composition models and there are three operational "chemical" weather services, two covering Europe and Italy [3, 4], and one 
covering Northern Italy [5]. In this work we report a first validation of the ForeChem service [4], recently developed in the frame of the QUITSAT (Air Quality with Integration of Remote Sensing from Ground and Satellite and Models, http://www.quitsat.it/) project funded by the Italian Space Agency (ASI).

\section{MM5 and CHIMERE models}

Meteorological input to the system is provided by the MM5 model [6] run on two domains covering Western Europe at $36 \mathrm{~km}$ horizontal resolution and Italy at $12 \mathrm{~km}$ resolution (Fig. 1). In the vertical, the model has 32 terrain-following $\sigma$ levels extending up to $\sim 100 \mathrm{hPa}$, with first 4 layers below $200 \mathrm{~m}$ altitude and first 10 below $1 \mathrm{~km}$ altitude. The following choices of main parameterizations are adopted: Reisner 2 microphysics, Grell cumulus scheme, MRF planetary boundary layer, RRTM radiation, Noah land-surface scheme.

The CHIMERE chemistry-transport model [7] uses the meteorological input from MM5, hourly emission inventories and boundary conditions to simulate the chemical state (gas and aerosol phase) of the troposphere over the two domains of interest, Europe and Italy, at $0.5^{\circ}$ and $0.15^{\circ}$ horizontal resolution, respectively. In the vertical, the model has 8 terrain-following $\sigma$-levels extending up to $500 \mathrm{hPa}$, with first levels having an approximate height of 40, 100 and $180 \mathrm{~m}$. Anthropogenic emissions ( $\mathrm{CO}, \mathrm{NOx}, \mathrm{SOx}, \mathrm{NMVOCs}$, and $\mathrm{NH}_{3}$ ) and particulate matter $\left(\mathrm{PM}_{10}\right.$ and $\left.\mathrm{PM}_{2.5}\right)$ are taken from EMEP ${ }^{1}$ expert emissions at continental scale and from CTN-ACE (Italian National Focal Point on Atmospheric Emissions) activity at Italian scale. Biogenic emissions for isoprene and monoterpenes are calculated with MEGAN model [8]. Aerosol primary and secondary (inorganic and organic) species are simulated in 8 internally mixed bins [7].
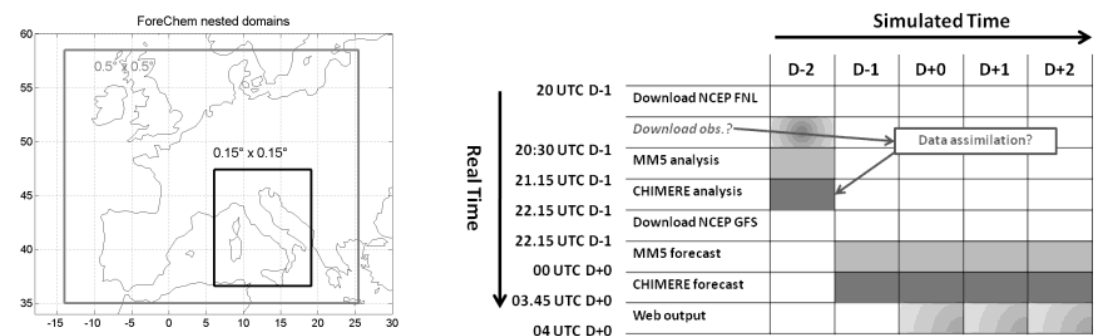

Fig. 1. Left: ForeChem nested domains of simulation. Right: ForeChem data flow and timings.

The MM5-CHIMERE modelling system is setup over a 4-processors Linux platform and runs automatically everyday in two main steps: analysis and forecast mode. The data flow is schematically represented in Fig. 1. In future developments, the system may accommodate a chemical data assimilation procedure during the analysis step, in case of availability of near-real time observations.

${ }^{1}$ http://www.ceip.at/emission-data-webdab/emissions-used-in-emep-models/ 


\section{Model Validation July 2007}

We run the ForeChem system for the period 19 June-15 July 2007, we discard the first two weeks as model spin-up, and compare the results for 3-15 July with ground observations of $\mathrm{O}_{3}, \mathrm{PM}_{10}$ and $\mathrm{PM}_{2.5}$ from $\mathrm{EMEP}^{2}$ and Airbase ${ }^{3}$ databases. We consider for comparison only rural, suburban, and urban background stations, since industrial and traffic stations are not representative of the simulated spatial scale (maximum horizontal resolution $\sim 12 \mathrm{~km}$ ).

In Table 1 we show statistics of comparison at continental scale. Ozone maximum is reproduced with a small positive bias $<10 \%$ and mean correlation up to 0.76 . PM levels are underestimated by $30-40 \%$ and with a mean correlation up to 0.59 . In Table 2 we show statistics on Italian high-resolution domain. Results for EMEP database are not shown, because only two stations are available in Italy. Average ozone maximum is much higher than continental value, and the model is able to capture this variability with a positive bias of $10 \%$ and a correlation of 0.71. PM levels are also higher than continental average, but the model does not reproduce this feature, indeed its negative bias is generally higher than that seen for the continental scale, and temporal correlation is lower.

Table 1. Comparison of EMEP and AirBase observations with ForeChem results, for 3-15 July 2007 at continental scale. Indices are: $\mathrm{N}=$ number of available stations, $\mathrm{OBS}=$ mean observed value, $\mathrm{MOD}=$ mean modelled value, $\mathrm{MB}=$ Mean Bias, $\mathrm{NMB}=$ Normalized Mean Bias, $\mathrm{RMSE}$ $=$ Root Mean Square Error, CORR $=$ temporal correlation .

\begin{tabular}{lcccccccc}
\hline Species & DB & $\mathrm{N}$ & OBS & MOD & MB & NMB & RMSE & CORR \\
\hline O3 max & & & $\mu \mathrm{g} / \mathrm{m}^{3}$ & $\mu \mathrm{g} / \mathrm{m}^{3}$ & $\mu \mathrm{g} / \mathrm{m}^{3}$ & $\%$ & $\mu \mathrm{g} / \mathrm{m}^{3}$ & \\
O3 max & AirBase & 1145 & 87.8 & 90.3 & 1.6 & 5.3 & 15.7 & 0.59 \\
PM10 daily & EMEP & 20 & 14.0 & 8.4 & -5.7 & -34.0 & 8.8 & 0.58 \\
PM10 daily & AirBase & 937 & 16.5 & 8.4 & -8.2 & -44.2 & 9.5 & 0.59 \\
PM2.5 daily & EMEP & 15 & 9.7 & 5.3 & -4.4 & -35.0 & 6.2 & 0.54 \\
PM2.5 daily & AirBase & 145 & 9.0 & 5.2 & -4.1 & -27.5 & 5.8 & 0.43 \\
\hline
\end{tabular}

Table 2. Same as Table 1, but on the Italian high-resolution domain.

\begin{tabular}{lcccccccc}
\hline Species & DB & $\mathrm{N}$ & OBS & MOD & MB & NMB & RMSE & CORR \\
\hline & & & $\mu \mathrm{g} / \mathrm{m}^{3}$ & $\mu \mathrm{g} / \mathrm{m}^{3}$ & $\mu \mathrm{g} / \mathrm{m}^{3}$ & $\%$ & $\mu \mathrm{g} / \mathrm{m}^{3}$ & \\
O3 max & AirBase & 190 & 113.0 & 119.0 & 5.5 & 9.9 & 22.0 & 0.71 \\
PM10 daily & AirBase & 103 & 19.5 & 8.2 & -11.4 & -55.8 & 12.9 & 0.52 \\
PM2.5 daily & AirBase & 11 & 10.3 & 5.5 & -4.7 & -35.6 & 5.8 & 0.37 \\
\hline
\end{tabular}

\footnotetext{
${ }^{2}$ http://tarantula.nilu.no/projects/ccc/emepdata.html

3 http://www.eea.europa.eu/data-and-maps/data/airbase-the-european-air-qualitydatabase-2
} 
Further analysis of the ozone bias, reveals that positive bias is mostly due to overestimation of values at lower end of distribution, while values at higher end are slightly underestimated and have an higher RMSE (Fig. 2a, left panel). On the other hand, the correlation increases with increasing maximum observed concentration. The model' skills degrade slowly with forecast lead time (Fig. 2, right panel). Regarding PM (Fig. 2b), it comes out that model errors increase with increasing observed PM value, being very poor at higher end of distribution.

Future work will extend this preliminary analysis to a longer simulation, including also a winter period, and will include further statistical indices to evaluate model prediction skills in terms of human health protection [10].

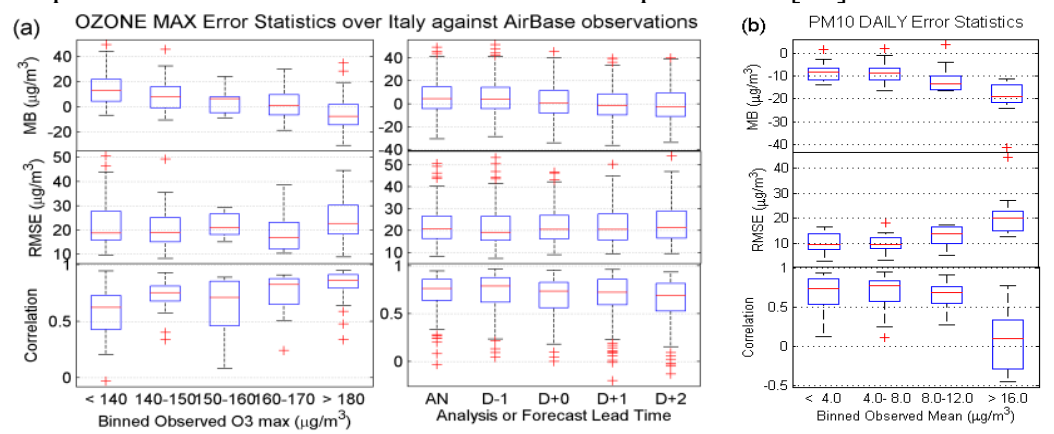

Fig. 2. Error statistics of simulated (a) $\mathrm{O} 3$ max and (b) daily PM10 against AirBase observations over high-resolution Italian domain. Whisker plots denote median, $25^{\text {th }}$ and $75^{\text {th }}$ percentiles, $1.5 \times$ (inter-quartile range), and outliers.

Acknowledgments The work is part of the Pilot Project QUITSAT, funded by the Italian Space Agency (ASI), contract I/035/06/0 - http://www.quitsat.it

\section{References}

[1] Menut, L., Bessagnet, B: Atmospheric composition forecasting in Europe, Ann. Geophys., 28, 61-74 (2010)

[2] Directive on Ambient Air Quality and Cleaner Air for Europe, Directive 2008/50/EC of the European Parliament and of the Council (2008)

[3] LaMiaAria, http://www.lamiaaria.it/

[4] ForeChem, http://pumpkin.aquila.infn.it/forechem/

[5] ARPA (Regional Environmental Protection) Emilia Romagna, http://www.arpa.emr.it/aria/

[6] Dudhia, J.: A nonhydrostatic version of the Penn State/NCAR mesoscale model: Validation tests and simulation of an Atlantic cyclone and cold front. Mon. Wea. Rev., 121, 1493-1513, (1993)

[7] Bessagnet, B., et al.: Regional modeling of carbonaceous aerosols over Europe - Focus on Secondary Organic Aerosols, J. Atmos. Chem., 61, 175-202, (2008)

[8] Guenther, A., Karl, T., Harley, P., Wiedinmyer, C., Palmer, P. I., and Geron, C.: Estimates of global terrestrial isoprene emissions using MEGAN (Model of Emissions of Gases and Aerosols from Nature), Atmos. Chem. Phys., 6, 3181-3210 (2006)

[9] Dabbert, W. F., et al.: USWRP workshop on air quality forecasting, Bull. Am. Met. Soc., 87, 215-221 (2006)

[10] Eder, B., et al.: Using National Air Quality Forecast guidance to develop local Air Quality Index forecasts, Bull. Am. Met. Soc., 91, 313-325 (2010) 